achieved in toilet, dressing, feeding, bathing and general mobility. The author apologises at one point for being platitudinous, but no apology is needed. The book is forthright, most helpful and very readable.

The final eight chapters, whilst designed primarily to deal with the problem of getting people back into industry or at any rate living something like a normal life, will be equally helpful to those, who because of the severity of their disabilities, will never recover or be able to do much for themselves.

One fear of the handicapped is that they will be shut off from their fellows and will be regarded as 'different' from the rest of society. This book will assist in some measure to show how they may be integrated into the life of the community and give a meaning and purpose to life. It is said that the special privilege of the doctor is 'to heal sometimes, to relieve often and to comfort always'. Dr. Russell Grant, by his work for the handicapped and by sharing in this book his thoughts and experiences with the world, is surely healing, relieving and comforting.

\section{Systemic Lupus Erythematosus}

Daniel L. Larson, M.D. Pp. viii + 212 , illustrated. Boston, Mass: Little, Brown. London: J. \& A. Churchill. 1962. 55s.

During the last 20 years, about 500 patients attending the Presbyterian Hospital, New York City have been suspected of having systemic lupus erythematosus. In 200 of these patients the diagnosis was established by a compatible clinical picture, post-mortem findings or the demonstration of the circulating lupus erythematosus factor. This monograph is an analysis of the clinical, laboratory and pathological features of the disease in this group of 200 patients. In view of the wealth of clinical material at his disposal and the care with which the patients were observed over the years, the author can be precise and dogmatic concerning the various clinical features, which are exhaustively dealt with under the heading of the various systems of the body on pages 21 to I 16 . The laboratory data (pages I 19 to 155 ) include discussions of the lupus cell factor, anaemia, leucopænia, thrombocytopænia and the biological false positive tests for syphilis.

Despite the longterm follow-up in this series, the author finds difficulty in assessing the prognosis in any given patient because of the great variability in the clinical course of systemic lupus erythematosus. From the data available it would seem that the onset of renal insufficiency and the appearance of congestive heart failure offer the greatest threat to life itself by the disease process. Infections were frequent terminal complications, possibly provoked by corticosteroid therapy. Lesions of the gastrointestinal tract leading to death were not common, but were of importance because they were also probably related to high doses of corticosteroids and salicylates rather than to the underlying disease.

In the Presbyterian Hospital series, there has been no systematic study to compare the effects of one type of anti-inflammatory agent with another. The author recommends reserving corticosteroid therapy for lesions which may threaten life.

There are 229 references to give added weight to an authoritative review of a difficult subject.

\section{Operative Surgery Revision}

John J. Shipman. Pp. viii + 172. London:

H. K. Lewis. 1962. 21s.

This new publication of 166 pages is offered as an aid to the harassed final Fellowship candidate in revising his operative surgery. This book is not intended to replace the standard works in operative surgery but mainly to facilitate revision. There are no illustrations, but the essential steps of the operations are clearly set out.

In addition to General Surgery there are sections on Thoracic Surgery, Urology, Neurosurgery, Otology, Ophthalmology, Orthopædics, and Vascular Surgery. Some rare operations are included, but the ground is well covered and the candidate is unlikely to be asked any operative surgery he will not find described here.

The examiners will not approve of the rather limited resection described for carcinoma of the transverse colon, nor the omission in Mayos operation for umbilical hernia, of lateral extensions into the rectus sheath on either side, the extent of which provides a good overlap and a sound repair. The Keetley-Torek operation is described to the exclusion of other orchidopexies and loop cholecyst-jejunostomy with enteroanastomosis is preferred to the more satisfactory Roux-en-Y cholecystjejunostomy for palliation in malignant obstruction of the lower end of the common bile duct:

In addition to the clearly described steps of operations there are helpful notes on some of the operations regarding indications, contra-indications, choice of incisions, difficulties and dangers, which the candidate will find helpful even after the Fellowship has been acquired.

This book is attractively produced and reasonably priced at a guinea and should be a most welcome help to final Fellowship candidates in the anxious days between the paper and the clinical.

Patrick Manson. The Father of Tropical Medicine

Sir Philip Manson-Bahr, C.M.G., M.D., F.R.C.P. (LOND.). British Men of Science series. Pp. viii + 192 illustrated. London: Thomas Nelson. 1962.

Sir Philip Manson-Bahr is an acknowledged heroworshipper of Patrick Manson, and in this short and simply written book he has brought out the significant facets of the life of this scientist. We are left to imagine some of the difficulties in trying to carry out scientific studies of patients, parasites and possible vectors in China with no apparatus worthy of the name. But the essential spirit of enquiry is illustrated and the care with which results were recorded, or specimens stored is shown over and over again. One phrase in this book sums up the spirit of Patrick Manson, the Father of tropical medicine: ' He made his opportunities whatever the conditions'. Manson was fascinated by the filarial embryos seen in the blood of some of his Chinese patients, and his studies showed the remarkable phenomenon of nocturnal periodicity of the embryos in the blood. He showed how an insect could harbour the larval parasites which underwent changes to prepare them for re-entry into a subject to carry disease. $\mathrm{He}$ wrote "It is the discrepancy which teaches if you would learn'. He also made observations on Paragonimiasis. But while busy with these researches he was concerned with the treatment of patients: smallpox, cholera, and leprosy sufferers all claimed his sympathies.

He was instrumental in the founding of the medical college of Hong Kong later to be incorporated into the University of Hong Kong. He came to London and soon had many pupils around him. It was from here that he supported and stimulated the researches of Ronald Ross in India into the transmission of malaria.

His record of research is most impressive but in addition he was concerned to place tropical medicine on a firm foundation of knowledge and to propagate that knowledge through the foundation of the School of 